\title{
História e filosofia da ciência na obra de George Sarton
}

\author{
History and philosophy of science in George Sartons work
}

\author{
AMÉLIA DE JESUS OLIVEIRA \\ Universidade Estadual de Campinas | UNICAMP
}

\begin{abstract}
RESUMO George Sarton tem sido sempre lembrado como um dos responsáveis pela institucionalização da disciplina de História da Ciência. Até o início dos anos 60, a crítica lhe é extremamente favorável e elogiosa, cedendo lugar a considerações restritivas que enfatizam a ausência de uma abordagem filosófica e analítica em seus escritos. Essas restrições se intensificam no contexto da nova historiografia da ciência, tal como anunciada por Thomas Kuhn. Procuramos, neste artigo, refletir sobre as considerações de alguns intérpretes de Sarton, analisando seu projeto grandioso em prol da criação da disciplina de história da ciência. Ao fazê-lo, buscamos mostrar como as críticas de alguns desses intérpretes são reveladoras da mudança ocorrida na história da ciência ao mesmo tempo em que suscitam a necessidade de se revisar seu papel na constituição da disciplina.
\end{abstract}

Palavras-chave história da ciência - nova historiografia - Sarton - Kuhn.

\begin{abstract}
George Sarton has always been remembered as one of those responsible for the institutionalization of the History of Science discipline. Until the early 60's criticism was extremely favorable and flattering, giving way to restrictive considerations that stress the absence of a philosophical and analytical approach in his writings. These restrictions are intensified under the new historiography of science, as announced by Thomas Kuhn. This paper reflects on the considerations of some of Sarton's interpreters and intends to analyze his great project towards the creation of the discipline of History of Science. In doing so, it tries to show how such criticisms reveal the change that occurred in the history of science as well as evoke the necessity of reviewing his role in the constitution of such discipline.
\end{abstract}

Key-words history of science - new historiography - Sarton - Kuhn.

\section{Introdução}

Em "History and the Philosopher of Science", 'Bernard Cohen cita A estrutura das revoluções científicas, de Thomas Kuhn, como um exemplo dos escritos histórico-filosóficos dominantes em sua época, que dificilmente poderiam ser identificados como pertencentes a um campo determinado por suas mais notáveis contribuições. Somente a passagem do tempo, ele afirma, poderia indicar se esses escritos primam por suas contribuições à história ou à filosofia da ciência.

Passado algum tempo, podemos perceber que a consideração de Bernard Cohen é interessante não só porque coloca em relevo a importância da história da ciência na obra mor de Kuhn, mas também porque dá indícios do quadro geral das reflexões sobre o empreendimento científico em momento de mudanças tanto na história quanto na filosofia da ciência. Nesse contexto de mudança, a relação entre essas disciplinas foi tema corrente de discussão, ${ }^{2}$ na qual 
Kuhn desempenha um papel expressivo. Em "As relações entre a história e a filosofia da ciência", texto publicado em A tensão essencia/ ${ }^{3}$ ele apresenta uma perspectiva supostamente inovadora na forma de se conceber não só a história como também a filosofia da ciência. 0 texto é de 1968- revisado em 1976 -, mas podemos retroceder a 1962, quando Kuhn, em $A$ estrutura das revoluções científicas, discorre sobre a mudança revolucionária ocorrente na história da ciência. Nessa obra, Kuhn sustentou que a história poderia desempenhar um papel crucial na compreensão do empreendimento científico e alterar substancialmente o próprio conceito de ciência. Porém, para tanto, a história da ciência tinha de ser uma nova história, diferente daquela expressa nos manuais históricos, cujo direcionamento principal era o de apresentar 0 aumento gradativo do conhecimento e as dificuldades encontradas no processo de sua acumulação.

A obra de Kuhn se tornou um marco para as discussões em história e filosofia da ciência e, muito comumente, uma referência para a avaliação das contribuições passadas nesses domínios. Isso certamente vale para a análise da obra do historiador George Sarton, sobre a qual procuramos, neste artigo, apresentar algumas características que delineiam seu contexto historiográfico e que permitem polemizar as críticas que comumente passaram a lhe ser atribuídas. Num primeiro momento (seção II), discutimos sobre o papel de Sarton na história da ciência ao longo de algumas décadas, procurando mostrar a gradativa mudança avaliativa pela qual sua obra passou, sobretudo após crítica de Kuhn. A seguir (seção III), buscamos identificar as principais motivações de Sarton com relação à história e à filosofia da ciência. Por fim (seção IV), discutimos o legado sartoniano após a chamada "revolução historiográfica", tal como anunciada por Kuhn. ${ }^{4}$

\section{O papel de George Sarton na história da ciência: uma história cambiante}

Quando observamos a literatura historiográfica sobre o desenvolvimento científico até o início dos anos 60, percebemos a trivialidade de se falar do papel fundamental de Sarton para a história da ciência. Além de se apresentar como uma usual referência para estudos históricos, seu nome é mencionado em livros, artigos e resenhas com teor elogioso e engrandecedor. Assim, é retratado como "eminente historiador", 5 " 0 mais penetrante de todos os historiadores", 6 " 0 representante máximo dos historiadores contemporâneos da ciência". ?

Hèléne Metzger, em textos de 1931 e 1936, ${ }^{8}$ afirma que a obra do historiador belga "faz pensar e desperta ideias"9 e deve ser lida com "alegria e reconhecimento", já que "nada do que Sarton escreve pode ser indiferente ao historiador da ciência". ${ }^{10}$ Para Millás Vallicrosa, Sarton prestou um "insubstituível serviço"11 para os historiadores da cultura, mostrando preocupação com todo o contexto investigado e o "desejo justiceiro em prol do legado da ciência medieval", que pode ser considerado um dos "seus méritos mais ilustres e honrosos". ${ }^{12}$ Num artigo publicado originalmente em 1956, ${ }^{13}$ Koyré menciona a contribuição das "grandes obras" de Sarton para a compreensão da ciência medieval.

Introduction to the History of Science, ${ }^{14}$ a obra mais citada de Sarton, é comumente retratada como "monumental"15 e como um "marco" na história da ciência. ${ }^{16}$ Duane Roller, que cita Duhem, Mieli e Sarton como promotores de "uma onda de inédito interesse pelo lugar da ciência em nossa cultura", vê a Introduction como uma "obra fundamental sobre o período anterior ao século XIV" ${ }^{17}$ Marshall Clagett atenta para "0 extraordinário conhecimento da ciência e do pensamento medievais evidentes na Introduction" ${ }^{18}$ Alistair Crombie indica a mesma obra como "um guia indispensável para qualquer estudante da ciência antiga e medieval", assegurando que o trabalho de Sarton "como compilador de fatos bibliográficos, biográficos e científicos" é "inestimável". ${ }^{19}$

A utilidade das bibliografias presentes na Introduction é também indicada por Thomas Kuhn em seu livro The Copernican Revolution, publicada em 1957. Nas notas bibliográficas, Kuhn relaciona Sarton entre outros pensadores cujas obras foram consultadas muitas vezes na composição do livro, esclarecendo que os cita nas outras notas somente na medida em que segue os tratamentos desses pensadores de uma maneira mais fiel..$^{20}$ 
Além da grandeza e conveniência dos textos de Sarton para a história da ciência, existe, nos textos dos intérpretes mencionados, quase que invariavelmente, referências ao trabalho incansável do historiador pela promoção da disciplina, com menções de claro reconhecimento à criação dos periódicos Isis e Osiris. A repercussão da obra de Sarton é bem ilustrada por Bernard Cohen, que lista as honras e medalhas concedidas ao grande historiador, bem como as sociedades e academias das quais ele fez parte e os títulos honorários que recebeu. ${ }^{21}$ Dorothy Stimson afirma, em 1962, que há "quarenta anos o nome de George Sarton tem sido praticamente sinônimo de história da ciência". ${ }^{22}$

A lista de intérpretes com visão elogiosa poderia facilmente ser estendida aqui. No entanto, os mencionados parecem-nos suficiente para ilustrar a avaliação bastante positiva e as perspectivas que assinalam a fertilidade das ideias sartonianas para o desenvolvimento da história da ciência. Isso é bem sintetizado nas palavras de Hellman: "Por suas palestras, livros e artigos, bem como através de seus alunos e seus colegas em todo o mundo, George Sarton espalhou sua interpretação da história da ciência. 0 caminho que marcou não será esquecido tão cedo". ${ }^{23}$

Nos textos mencionados até o momento, há, evidentemente, manifestações de diferentes níveis de enaltecimento da obra sartoniana, importando, de qualquer modo, o seu assegurado valor para a história da ciência. Somente os textos de Clagett e Crombie apresentam considerações restritivas. Para Clagett, devido à abordagem bibliográfica e classificatória, os escritos sartonianos não apresentam uma discussão das ideias e das atividades científicas. A seu ver, o historiador belga "percebeu isso e tentou satisfazer a necessidade de uma discussão prefaciando cada parte do trabalho com uma longa introdução", mas não sanou completamente a falha, já que "essas introduções não atingem o objetivo de uma avaliação metódica e reflexiva do desenvolvimento da ciência". ${ }^{24}$

A ressalva de Crombie ao legado sartoniano é um pouco mais enérgica e evoca a abordagem "filosófica e analítica" da história da ciência então presente nos trabalhos dos mais jovens estudiosos na área, que estariam iluminando o desenvolvimento e o caráter do pensamento científico. Sua consideração é a de que "Dr. Sarton foi um homem mais de fatos do que de ideias." Então sugere que "um crítico severo poderia até mesmo afirmar que a abordagem de Sarton poderia ter matado facilmente o estudo de história da ciência, que respira através das ideias, ao sufocá-la debaixo de uma montanha de fatos não relacionados e não interpretados". ${ }^{25}$ Considera, entretanto, que tal crítica seria extrema demais e valoriza o trabalho do historiador 'compilador de fatos'.

0 teor das análises de Clagett e Crombie dá indícios de uma mudança na historiografia da ciência em processo. Devemos lembrar que o texto de Clagett é do mesmo mês e ano (setembro de 1957) do congresso da Universidade de Wisconsin, que reuniu setenta e dois historiadores para discutir criticamente problemas na história da ciência, dentre os quais estavam, supostamente, os jovens estudiosos que faziam a abordagem "filosófica e analítica" a que Crombie se referiu na sua resenha de $1959 .{ }^{26}$

Kuhn, que identificou a mudança ocorrente e a divulgou nos anos 60 , tornou-se uma referência para o julgamento da obra de Sarton. Helge Kragh, por exemplo, evoca a obra kuhniana para falar sobre a concepção histórica de Sarton que, em seu ponto de vista, é, segundo padrões modernos, "um tanto ingênua e surpreendemente a-histórica". ${ }^{27}$ Rupert Hall, em texto que cita Kuhn e Koyré como pensadores que mostravam que a história da ciência poderia se tornar história "de verdade", critica a história da ciência mais antiga e, apesar de considerar que Sarton foi um homem de grande saber, delibera que não se pode deixar de indagar se ele foi, alguma vez, um historiador. ${ }^{28}$

As referências à obra de Sarton, como podemos observar, têm sempre como foco sua principal obra, Introduction to the History of Science, que, no conjunto de seus volumes, computa mais de 4.000 páginas. Edward Grant a descreve como "ainda indispensável, embora levemente datada", fornecedora de "uma vasta quantidade de informações biográficas e bibliográficas" e como "um trabalho verdadeiramente monumental cobrindo todo aspecto da ciência antiga e medieval até 1400". ${ }^{29} \mathrm{~A}$ caracterização da obra como fornecedora de dados biográficos e bibliográficos nem sempre é positiva. Rupert Hall, por exemplo, após afirmar que Sarton "adorava biografia e, especialmente, bibliografia", considera que os historiadores tradicionais não perceberam que "o conhecimento histórico de primeira classe não produz, por si mesmo, história de primeira classe"; que a "história real é mais do que registrar fatos sobre o passado ou mesmo retornar às fontes e considerar o que elas realmente dizem, em vez de relatar minuciosamente a tradição". ${ }^{0}$ 
0 que se pode observar nas análises da obra de Sarton que se seguiram à mudança historiográfica é uma crescente desaprovação ao tipo de história que ele praticou e poucos são os trabalhos recentes dedicados à analise de sua obra. ${ }^{31}$ De eminente historiador, ele passou a ser visto somente como um trabalhador incansável na criação da disciplina de História da ciência. É dessa forma que a análise que recai sobre seu trabalho como historiador nos permite acompanhar a gradativa mudança que ocorre no desenvolvimento da história da ciência.

\title{
A obra de Sarton em consonância com o projeto do estabelecimento de uma disciplina
}

A observação de Clagett, mencionada acima, de que Sarton percebeu o caráter lacunar de sua obra com relação à ausência de discussão das atividades e ideias científicas e de que, por isso, prefaciou suas obras com grandes introduções merece ser examinada. Se observarmos, por exemplo, os volumes da Introduction, veremos que, de fato, existem textos reflexivos intermediando as sequências de dados científicos, biográficos e bibliográficos de cada capítulo. Contudo, a visão de que Sarton teria escrito prefácios para sanar uma 'falha' de sua obra, não encontra amparo em seus textos.

No prefácio ao livro A History of Science - Ancient Science through the Golden Age of Greece, Sarton reflete sobre o propósito e a avaliação de sua maior obra:

\begin{abstract}
Muitos anos atrás, logo depois da publicação do volume 1 de minha Introduction, encontrei um de meus antigos estudantes [...] Depois de alguma hesitação, ele me disse: "Comprei um exemplar de sua Introduction e nunca fiquei tão desapontado em minha vida. Lembro-me de suas aulas, que eram vívidas e animadas e esperava encontrar reflexões delas em seu grande volume, mas ao invés disso não encontrei nada além de afirmações secas que me desanimaram”. Tentei explicar a ele o propósito de minha Introduction [...] que grande parte dela não era para ser lida, mas para ser consultada e disse finalmente: "Talvez eu seja capaz de escrever um livro que agrade mais você". ${ }^{32}$
\end{abstract}

A informação de que grande parte da Introduction "não era para ser lida, mas para ser consultada" consta no capítulo introdutório dessa obra, precisamente no primeiro parágrafo. Aí lemos: "A primeira seção de cada capítulo e este capítulo introdutório são as únicas partes de meu trabalho que foram planejadas para uma leitura contínua. 0 restante do material é incorporado para propósitos de estudo e referência". ${ }^{33}$ Essa consideração, como tentaremos mostrar no que segue, está em perfeita consonância com seu projeto de estabelecer a disciplina de história da ciência e dá indícios de como ele imaginava poder fazer isso.

Antes de explorarmos o capítulo introdutório de 1927, merece consideração um texto de maio de 1921, publicado em Isis, no qual Sarton apresenta uma nota preliminar à obra que pretendia produzir: uma introdução à história e à filosofia da ciência. Nesse texto, ele relata o seu velho desígnio de escrever a obra e apresenta seu propósito: 0 de "estabelecer a história das ciências como uma disciplina independente e organizada". ${ }^{44}$ Antes mesmo de iniciar seu empreendimento, Sarton já admite a dificuldade de sua execução, quando afirma: "Inicialmente pensei que, tão logo meu material estivesse devidamente classificado, a escrita seria relativamente fácil, pois, é fato que a Introduction existe potencialmente em minhas notas. Contudo, descobri uma vez mais que há um longo, longo caminho de tal potencialidade para a realidade.". ${ }^{5}$

Na sequência, esclarece que resolveu publicar o texto preliminar porque percebeu que sua obra iria demandar mais tempo do que ele tinha imaginado e porque queria explicitar seu propósito de maneira acurada e completa, já que pretendia submeter seu trabalho para análise crítica de vários especialistas. Sarton apresenta seu projeto como extremamente relevante, dada à falta de organização dos estudos históricos. Os existentes normalmente compreendiam uma ciência particular ou grupo de ciências. Não existiam "manuais acima do grau elementar e quase nenhuma 
das ferramentas intelectuais sem os quais a pesquisa é necessariamente muito vagarosa" ${ }^{36}$ Assim, pode-se verificar que seu propósito era mesmo o de confeccionar um manual, um manual como ponto de partida para a viabilização de estudos históricos sobre as ciências:

Para estabelecer a história da ciência como uma disciplina independente, nosso primeiro passo deve ser o de definir esses estudos, explicar cuidadosamente o conhecimento que eles implicam, os métodos que devem ser usados para promovê-los e finalmente, fazer um balanço do que já foi feito e chamar a atenção para o que resta a ser feito. Minha introdução será tal pesquisa preliminar. ${ }^{37}$

A obra foi planejada para conter um sumário da ciência em geral e da história de cada ciência particular. Sarton considerou que

a história da ciência não é importante somente enquanto a história de uma das mais elevadas das atividades humanas, mas é ainda mais porque é a base natural para a filosofia da ciência e, de fato, de qualquer filosofia positivista. [...] Pois tão logo percebemos que nosso conhecimento da natureza e do homem não pode ser completa a menos que combinemos informações históricas com as científicas, a história da ciência se torna, por assim dizer, a pedra de toque de toda a estrutura. [...]

O objetivo da introdução é fornecer uma prova completa dessas asserções, fazer uma pesquisa preliminar, fornecer ao estudante uma bibliografia sintética de todo o campo e uma chave mestra para os problemas desse campo. ${ }^{38}$

Segundo Sarton, poucos cientistas e historiadores percebiam a importância do estudo da história da ciência e, por esse motivo, era necessário fornecer uma base para as pesquisas históricas ainda não existentes. Quando observamos o plano de trabalho para seu empreendimento, verificamos a grandiosidade do projeto de Sarton, que ainda pretendia discutir a definição de ciência, seu significado e limitações, seu fazer histórico, sua organização (interna, externa e técnica), e, ainda, discorrer sobre a filosofia da ciência. ${ }^{39}$

A nota preliminar apresentada por Sarton indica que ele planejou mesmo fornecer uma compilação bibliográfica de toda a história da ciência e não pretendia, nessa obra, fornecer novas abordagens sobre estudos já existentes. Para alguns assuntos, ele previa uma investigação superficial, pois, do contrário, sua introdução, como ele afirma, "nunca estaria pronta". ${ }^{40}$

Sarton não escreveu a "Introdução à história e à filosofia e da ciência", mas somente uma introdução à história da ciência. E seu grande projeto não somente seguiu por rumos inesperados - tomou-lhe muito mais tempo do que 0 imaginado, o fez aprender línguas ${ }^{41}$ - mas também não apresentou, ao final, a discussão detalhada dos assuntos planejados e elencados em sua nota preliminar de 1921.

No capítulo introdutório da Introduction, ele discute, de modo bastante geral, o conceito de ciência e de história da ciência. Comparando o conhecimento científico com outros tipos de conhecimento, Sarton considera que não há dúvida de que a ciência propicia um "conhecimento mais extensivo e mais acurado"; que a "aquisição e a sistematização do conhecimento positivo é a única atividade humana que é verdadeiramente cumulativa e progressiva". ${ }^{2}$ Já a história da ciência, em sua visão, "pode sempre ser considerada sob dois aspectos: ou positivamente como a gradual revelação da verdade, 0 aumento de luz; ou negativamente como triunfo progressivo sobre 0 erro e a superstição, a diminuição da escuridão" ${ }^{43}$ Sua ênfase permanece na defesa e promoção dos estudos históricos do empreendimento científico, sem os quais a história da civilização humana não estaria completa. Ao observarmos o conteúdo do capítulo introdutório da Introduction em comparação ao projeto exposto na "nota preliminar" de 1921, a impressão que temos é a de que Sarton não conseguiu levar adiante seu projeto de discutir metódica e reflexivamente o desenvolvimento da ciência e não a de que tenha inserido textos introdutórios para sanar uma falha percebida postumamente. Tal como exposta em "potência" na sua primeira divulgação, no texto de 1921, a Introduction foi uma obra concebida para ser uma fonte 
de dados biográficos, bibliográficos e científicos, um manual necessário para o estabelecimento da nova disciplina e, além disso, fornecer subsídios para uma análise de problemas filosóficos e históricos. Ao fim, parece-nos que, se não conseguiu realizar plenamente seus propósitos, Sarton se manteve direcionado para atingir o principal deles, em meio às dificuldades que encontrou, tendo expressado isso em diversas partes de sua obra.

No prefácio ao segundo volume da Introduction, publicado em 1931, Sarton afirma que não foi seu objetivo constituir "meramente uma bibliografia" 44 com aquele trabalho, mas que pretendeu esboçar um mapa da vida intelectual da Idade Média, fornecendo uma estrutura sintética de todo o período, sem se deter em fatos específicos. 0 que lhe interessava, diz ele, "do início ao fim, era a inter-relação desses fatos, sua disposição - não uma parte singular, mas o todo" ${ }^{45} \mathrm{Em}$ retrospectiva, ele avalia: "Esse foi um projeto ambicioso, talvez ambicioso demais, difícil e desencorajante em muitos aspectos; contudo, tranquilizante por outro. Ninguém pode ter gasto tanto tempo quanto eu na averiguação de inumeráveis pequenos fatos sem se mostrar um tanto cético quanto à possibilidade de alcançar a verdade para cada um deles" . ${ }^{4}$

Devido à amplitude de seu objetivo, Sarton reconheceu que suas pesquisas poderiam parecer muito superficiais à primeira vista. Para afastar esse julgamento, ele compara o trabalho de um cartógrafo que prepara um mapa da América com o de outro, que elabora um mapa de sua própria aldeia. Poder-se-ia afirmar que o trabalho do primeiro é mais superficial que o do segundo. Contudo, a seu ver, essa avaliação depende do material que se tem à mão e da integridade do cartógrafo. 0 que se perde em precisão é compensado pela generalidade em outro. Sua ambição, ele afirma, era a de "fornecer uma estrutura para o estudo da ciência e do pensamento medieval e capacitar estudiosos a conhecer tão exatamente quanto possível o estado de nosso conhecimento atual em cada tópico" ${ }^{47}$

A indicação de abundantes referências bibliográficas se daria em virtude da possibilidade dos pesquisadores futuros poderem continuar, completar e corrigir suas investigações e ainda ao fato das contribuições para a história da ciência estarem "espalhadas em uma infinidade de periódicos e coleções de todo tipo (científicas, históricas, filosóficas, filológicas, orientalistas, econômicas, religiosas, etc.)". ${ }^{48}$

Além da grande extensão da área investigada, Sarton indica outras razões para amenizar eventuais erros e omissões. Uma é a de que o trabalho que tinha para realizar era "dever pioneiro"; a outra é de que ele estava "não somente pronto, mas ansioso para reparar seus erros, fornecendo completa publicidade deles". ${ }^{49} \mathrm{E}$ aí Sarton fornece uma lista de erratas e adendos publicados após o primeiro volume da Introduction nas bibliografias críticas de Isis.

No prefácio de seu terceiro e último volume da Introduction, ele apresenta correções e adendos aos volumes anteriores, afirmando que uma "boa bibliografia é lenta, muito lenta". ${ }^{50}$ No capítulo introdutório a esse mesmo volume, recorda seu projeto de fundação de um jornal e a de "composição de um manual, no qual os principais fatos seriam brevemente estudados juntamente com informações bibliográficos suficientes para facilitar estudos posteriores" ${ }^{51}$

É interessante ainda comparar a nota introdutória de 1921 e algumas observações que antecedem a lista de historiadores e filósofos da ciência, publicada em /sis, mais de trinta anos depois, quando Sarton afirma:

A história e a filosofia da ciência é um campo de enorme tamanho e complexidade e os estudiosos que se dedicam a ele devem restringir seus esforços a uma pequena parte. Como se tornam mestres de uma determinada parte no campo, tornam-se altamente competentes para criticar o trabalho feito por seus predecessores. Se eles compusessem a biografia de um ou mais desses predecessores, esclareceriam seu próprio conhecimento e prestariam um grande serviço para suas próprias disciplinas e seguidores. ${ }^{52}$

Como se pode observar, talvez muito em função da impossibilidade de completar seu projeto, Sarton reconheceu que os estudiosos deviam restringir seus esforços a uma pequena parte de todo o âmbito que tentou abarcar em suas pesquisas. Enquanto conhecedores de partes específicas, os estudiosos seriam "altamente competentes" para criticar 0 trabalho de seus antecessores. Sarton foi um predecessor para muitos estudiosos e os seus sucessores Thackray e Merton são alguns dos que se dedicaram a compor uma biografia sua e a analisar criticamente seu trabalho. Em uma passagem do texto em que discutem os paradoxos que envolvem a obra do historiador predecessor, afirmam: 
A influência de Sarton sobre a disciplina, para a qual labutou tão fielmente para criar, tem sido obscurecida cada vez mais. Ironicamente, seu monumento está, em função de sua natureza, se tornando progressivamente invisível para iniciantes no campo. Ao fundar uma revista, ao realçar uma bibliografia crítica, ao fazer grandes pesquisas, e acima de tudo, ao escrever a Introduction, ele estava criando elementos requeridos pela disciplina, não métodos para serem emulados ou produtos finais para serem exibidos. Contudo, ele fez mais do que meramente produzir ferramentas. ${ }^{53}$

A análise de Tackray e Merton, a nosso ver, apresenta um quadro mais verossímil da posição de Sarton na história da ciência. É uma ironia que sua obra tenha perdido o prestígio de que já desfrutou outrora. Uma vez estabelecida a disciplina de história da ciência, Sarton passou a ser reconhecido como seu fundador, mas bastante depreciado como historiador e muito em função de sua incansável compilação de fatos, de biografias e bibliografias. ${ }^{54}$

\section{O legado sartoniano para a história da ciência e a revolução historiográfica}

Das primeiras às últimas avaliações críticas, o estatuto da obra sartoniana sofreu uma alteração gradativa e significativa. 0 exame dessas avaliações indica diferentes concepções do que pode ser a história e filosofia da ciência. É compreensível que Metzger, em textos dos anos trinta, afirme que a obra do estudioso belga "faz pensar e desperta ideias" e deveria ser lida com reconhecimento; que Crombie, mais de vinte anos depois, reclame a ausência da análise filosófica e analítica da história da ciência na obra de Sarton.

A mudança pode ser percebida ainda nos textos de Bernard Cohen, citados acima. Como já mencionado, em 1957 ele escreve sobre a importância de Sarton para a história da ciência e, em 1977, sobre a aproximação da história e da filosofia da ciência, citando o livro de Kuhn como exemplo. Em seu livro posterior Revolutions in Science, publicado em 1985, Bernard Cohen, logo após citar Sarton como um dos primeiros fundadores da disciplina e como defensor da visão cumulativa do desenvolvimento científico, afirma que Kuhn, a partir de 1962, "alterou radicalmente nossa ideia de mudança científica" e que "poucos livros na história da ciência têm estimulado tanto interesse". ${ }^{55}$ Ele identifica uma variedade de análises acerca do desenvolvimento científico nos escritos de filósofos e historiadores da ciência e, em sua visão, Kuhn teve parte central no debate.

É bom lembrar que Kuhn não fez menções diretas a historiadores responsáveis por uma visão enganadora de ciência e carente de superação em seu texto mais famoso, embora tenha, por outro lado, indicado exemplos de pensadores que mudavam a escrita da história do desenvolvimento científico. ${ }^{56}$ É nos textos "A História da ciência" e "As relações entre História e a História da ciência", reunidos em $A$ tensão essencial que Kuhn indica nomes de historiadores que supostamente pertenciam à história da ciência tradicional e criticada em $A$ estrutura das revoluções científicas. E 0 nome de George Sarton é mencionado nesses textos como pertencente a uma tradição que concebia "0 avanço científico como o triunfo da razão sobre a superstição primitiva". ${ }^{57}$ Mesmo admitindo que essa tradição tenha apresentado estudos sérios e cuidadosos, alguns ainda "úteis", Kuhn considera que, além do autor e da data das descobertas, tais estudos trazem "poucas informações quanto ao conteúdo da ciência". 58

Kuhn admite ainda uma "dívida imensa" com Sarton por seu papel no estabelecimento da história da ciência enquanto uma especialidade. Contudo, afirma que a imagem que ele propagou dessa especialidade "continua a causar muito prejuízo, apesar de ter sido rejeitada há bastante tempo". ${ }^{59}$ Mais tarde, na longa entrevista publicada em O Caminho desde A estrutura, Kuhn reforça a diferença entre sua visão e a de Sarton, explicando que estava fazendo um tipo de história da ciência diferente da que fazia o historiador belga e revela que não teria dito as coisas que diria "hoje" (em 1995) a seu respeito. A seu ver, Sarton foi "certamente um grande homem, mas certamente um historiador whig"60 que concebia a ciência como "a maior conquista humana e modelo para tudo mais". ${ }^{61}$ 
É interessante notar que Kuhn, como Sarton, atentou para a necessidade dos estudos históricos do desenvolvimento científico, mas que recusou invariavelmente a concepção de ciência e de história de seu antecessor. Ao relembrar seu desinteresse pela história da ciência, que se manifestaria até por volta de 1948, Kuhn relata como concebia o papel do historiador em geral: "Para mim, nessa época, assim como para a maioria dos cientistas e dos filósofos, o historiador era a pessoa que coletava e averiguava fatos sobre o passado e posteriormente os organizava em ordem cronológica" ${ }^{62}$

Em sua reiterada defesa em prol dos estudos históricos, Kuhn sempre marcou a diferença entre a historiografia mais antiga e uma nova proposta historiográfica, segundo a qual a história é "um empreendimento explicativo, que leva à compreensão e deve, portanto, não apenas expor os fatos, mas também as conexões entre eles". ${ }^{63}$ Somente enquanto um empreendimento explicativo, a história poderia desempenhar um papel significativo para a compreensão da ciência; do contrário, a história serviria apenas ao filósofo da ciência como uma "fonte de exemplos de posições mantidas previamente". ${ }^{64}$ Em acordo com a visão kuhniana, Sarton foi o historiador que praticou esse tipo de história e que a difundiu. E, embora afirme que ninguém mais acredita que a história seja "mera crônica, uma coleção de fatos arranjados na ordem de suas ocorrências", ${ }^{65}$ Kuhn invariavelmente combateu a história tradicional, assinalando dificuldades e problemas a serem ainda superados. ${ }^{66}$

Seus textos historiográficos fornecem um esboço histórico do desenvolvimento do campo que contribui para situar a obra de Sarton na história da ciência e que indica a mudança gradativa nesse domínio. Comparando suas considerações críticas às de outros intérpretes de Sarton, é interessante notar que Kuhn foca sua crítica na noção de ciência. $\mathrm{Na}$ introdução de $A$ estrutura das revoluções científicas, ele afirmou que o objetivo dessa obra era o de fornecer "um esboço de um conceito de ciência bastante diferente que pode emergir dos registros históricos da própria atividade de pesquisa". ${ }^{67}$ E o novo conceito de ciência só poderia surgir a partir de um novo conceito de história, já em formação graças ao trabalho de alguns historiadores que alteravam significativamente o modo de retratar o passado da ciência.

Embora, conforme já afirmado acima, Kuhn apresente críticas a Sarton, chamando-0, inclusive de historiador whig, não podemos ignorar outras passagens de sua obra que tornam mais complexa a avaliação da obra desse historiador. A observação às notas bibliográficas presentes ao fim de The Copernican Revolution poderia suscitar questionamentos àquele que admitisse como verdadeira a oposição entre o 'velho' e o 'novo' historiador da ciência. Kuhn indica trabalhos de historiadores que the forneceram subsídios para o livro e entre eles o nome de Sarton aparece ao menos uma meia dúzia de vezes, sem ressalva alguma. Não se pode ignorar ainda que, quando Kuhn elenca os fatores decisivos para 0 aparecimento da nova historiografia da ciência, o nome de Sarton aparece associado ao terceiro deles: a tentativa da composição de uma história global da ciência. Kuhn avalia:

A experiência posterior indicou que as ciências não são, de fato, uma só, e mesmo a erudição super-humana, exigida por uma história da ciência geral, poderia dificilmente costurar sua evolução conjunta numa narrativa coerente. Mas a tentativa foi crucial, pois ressaltou a impossibilidade de atribuir, ao passado, as divisões do conhecimento existentes no currículo da ciência contemporânea. ${ }^{68}$

0 texto do qual essa consideração é extraída ("A história da ciência") é de 1968 e aqui Sarton tem um papel não só no estabelecimento da disciplina, mas também na mudança pela qual essa especialidade passou. 0 que se pode observar é que, em harmonia com as avaliações de outros intérpretes, a crítica de Kuhn vai, pouco a pouco, tornando-se mais severa. Da citação da Introduction sem ressalvas nas notas bibliográficas de The Copernican Revolution, de 1957, até entrevista de 1995, Kuhn foi alterando a avaliação da obra de Sarton negativamente e isso, certamente, decorreu em função da mudança historiográfica.

Na avaliação do legado sartoniano após o desenvolvimento da história da ciência, vale lembrar a expectativa geral que o próprio Sarton apresentou no segundo volume de sua Introduction, em 1931: "Se essa pesquisa não tivesse nenhum resultado senão o de desencorajar produções fúteis e supérfluas, ela já se justificaria; mas acredito que ela também estimulará melhores esforços na direção correta. Quanto mais rápido sua estrutura se tornar obsoleta por meio de novas pesquisas, mais feliz o autor ficará" ${ }^{69}$ 
Face às perspectivas temporais de Sarton quanto à repercussão de seu grandioso projeto, é possível conjecturar que seus sucessores foram felizes na corroboração de sua crença. Afinal, sua obra, além de ter se mostrado fonte para muitos historiadores, não passou ilesa às críticas de novas pesquisas e isso não consumiu muito tempo.

\section{Considerações finais}

Rupert Hall, questionando o estatuto da obra de Sarton enquanto história da ciência, afirmou que "não se pode esquecer ou perdoar completamente sua recusa em discutir as teorias fisiológicas de Galeno sob a argumentação de que elas eram inconstantes e absurdas!" ${ }^{70}$ Essa crítica a Sarton é sustentada por uma determinada concepção do que deveria ser a história da ciência no fim dos anos 60. Como em Kuhn, a crítica de Rupert Hall a Sarton está centrada em sua concepção de ciência e de história. Assim, a "real" história da ciência é uma história interpretativa e não simplesmente a procura, em todo tempo e lugar, do conhecimento positivo sistematizado. Ou seja, a crítica é atribuída em função de um novo conceito de ciência. Contudo, devemos considerar que esse novo conceito passou a ser admitido muito em função da mudança ocorrida gradativamente na história da ciência.

Sarton criticou o sábio Galeno porque ele não praticou a ciência moderna e foi posteriormente criticado como historiador porque ele não praticou a história tal como entendida no contexto contemporâneo de seus críticos. Ao olharmos para os resultados de historiadores passados, poderíamos reclamar também uma atitude compreensiva. Sabemos que, segundo Kuhn, a compreensão, por exemplo, da física aristotélica, não pode ser levada a cabo sem uma atenção ao contexto histórico investigado, sem a admissão de uma mudança significativa de visão de mundo e violação da linguagem. Diria Kuhn que, embora incomensurável com outras visões, a tradição aristotélica era também científica. A nova historiografia poderia dar ensejo a uma nova visão de ciência. E aqui parece pertinente indagar: uma nova visão de ciência não seria fruto também de um processo lento de mudança da própria ciência? Não são as revoluções que alteram significativamente a linguagem da ciência? Poder-se-ia argumentar que, após a revolução historiográfica, as visões de Sarton e Kuhn, ainda que incompatíveis ou mesmo incomensuráveis, são igualmente históricas. Se não é legítimo ao historiador da ciência reconstituir o passado com um determinado conceito de ciência previamente determinado, por que deveria ele reconstituir o passado da história do desenvolvimento científico com um determinado conceito de história?

Poder-se-ia argumentar ainda que Sarton insistiu numa determinada visão de ciência em época em que os cânones historiográficos do desenvolvimento científico se modificavam. Contudo, não seria a insistência sartoniana compreensível, mais uma vez, em comparação com as evidências de mudança em ciência, quando cientistas insistem em manter uma determinada teoria com peso na tradição passada? Parece plausível afirmar que, assim como na ciência, em que a mudança conceitual aparece como pré-requisito para a compreensão da atividade científica passada, a compreensão da história do passado não se faz sem a admissão de que importantes conceitos da historiografia se alteraram.

Contudo, a recusa da concepção dos críticos de Sarton sob o argumento de que eles padecem da mesma visão whig que combateram não levaria também a uma postura presentista? Afinal - como podemos observar - as críticas a Sarton emergem num momento de mudança e evoluem gradativamente, mostrando-se úteis (talvez mesmo necessárias) no processo da passagem de uma visão a outra. Uma vez prevalecente, a nova visão historiográfica nos permite reavaliar Sarton, seu empreendimento e a visão de seus críticos. Mas essa avaliação é também carregada de padrões e valores presentes. Poderia ser diferente?

É por isso que o reconhecimento de que Sarton imaginava compor uma "Introdução à história e à filosofia da ciência", de que tenha defendido que a história da ciência é a base para a filosofia da ciência, entre outras coisas, é surpreendente à primeira vista. De certo modo, podemos dizer que Sarton viveu o período de transição de uma história tradicional a uma nova história da ciência, e que, ainda se mostrando como um típico representante da primeira, não se manteve completamente ileso às mudanças então em curso. 
Se a visão histórica de Sarton causou muito prejuízo, como afirma Kuhn, é certo que seu trabalho pioneiro de compilador de fatos foi fonte para muitos historiadores (certamente para o próprio Kuhn) que reescreveram a história da ciência. Quando observamos as considerações de Sarton sobre o empreendimento de compor uma introdução para a história da ciência, podemos dizer que ele estava ciente das limitações de sua obra. Esse parece ser também 0 entendimento de Drabkin, que em polêmica com Clark no congresso de 1957, em Wisconsin, afirma:

[...] na medida em que Introduction não trata suficientemente das relações lógicas e sistemáticas de ideias de uma época a outra, ela não pode ser considerada (e certamente não foi planejada para ser) uma história da ciência em grande escala, mas antes uma introdução, um repertório de materiais necessários para a escrita de tal história. ${ }^{71}$

Os estudiosos do passado da ciência que, a partir de Sarton, puderam ser denominados oficialmente de 'historiadores da ciência' não tomaram a maior obra de Sarton como exemplo de história do desenvolvimento científico, mas a tiveram como base para desenvolver o que consideraram ser 'a' história da ciência. Os críticos sartonianos, após a obra de Kuhn, não reclamaram a ausência de uma discussão filosófica na obra de Sarton (como Crombie ou Clagett), mas combateram justamente a visão de Sarton sobre assuntos caros à filosofia da ciência, tais como o próprio conceito de ciência, de método e de progresso científico. A crítica não se dirigiu somente à história da ciência, mas à filosofia positivista de Augusto Comte, da qual Sarton se mostrou partidário ${ }^{72}$. Nesse contexto, mais uma vez, a contraposição de visões e a crítica ferrenha à visão sartoniana foram necessárias aos proponentes da mudança em suas realizações e se mostraram úteis posteriormente para a compreensão dessa mudança. Sarton não escreveu a introdução à filosofa da ciência que planejou, mas tomou parte significativa do debate que se seguiu acerca da necessária relação entre a história e a filosofia da ciência, num contexto em que 'história da ciência' e 'filosofia da ciência' tinham outros referentes.

Em "Philosophy of Science and History of Science", Thomas Nickles afirma:

Admitir que não se pode ser um historiador antiwhig puro no sentido de Herbert Butterfield não significa que se possa voltar o relógio para a visão de George Sarton no campo da história e filosofia da ciência. [...] Não há dúvida de que é importante compreender os desenvolvimentos históricos em seus próprios termos. Meu argumento é que uma fase importante no desenvolvimento da história da ciência está acabada e que agora é hora de seguir em frente. ${ }^{73}$

Nossa tentativa de investigar a obra de Sarton é pautada pelo que ele tem a dizer em seus próprios termos, uma tentativa que talvez revigore a necessidade de insistir ainda, após Sarton, Kuhn e tantos outros, na importância do papel da história da ciência para os estudos em filosofia da ciência. E, se como afirma Nickles, "uma fase do desenvolvimento da história da ciência está acabada", Sarton é seguramente parte significativa dela, tanto pelo que representou por algum tempo, tanto pelo antimodelo que se tornou. 0 exame da mudança do estatuto de sua obra, ao longo de décadas, muito pode revelar sobre o que tem sido a história e a filosofia da ciência. 


\section{Notas e referências bibliográficas}

Amélia de Jesus Oliveira é pós-doutoranda em Filosofia (IFCH/UNICAMP). Este trabalho foi desenvolvido com apoio financeiro da Fundação de Amparo à Pesquisa

do Estado de São Paulo - FAPESP - Processo 2013/20172-0. E-mail: amelijeso@gmail.com

1 Texto publicado nos volumes que reúnem os trabalhos apresentados no simpósio sobre a estrutura das teorias científicas, realizado em Urbana, em 1969. Cf. BERNARD COHEN, I. History and the Philosopher of Science. In: SUPPE, Frederick (ed.), The Structure of Scientific Theories. 2 v. $2^{\text {a }}$ ed. Urbana: University of Illinois Press, 1977, p. 308.

2 Tome-se, como exemplos, os textos de: CLARK, J. The Philosophy of Science and the History of Science. In: CLAGETT M. (ed.). Critical Problems in the History of Science. Madison: University of Wisconsin Press, 1969 [1959], p. 103-140; SHEA, W. Why Historians of Science and Philosophers of Science should speak one another. Anais do Simpósio História e Filosofia da Ciência. ACIESP, n. 23, p. 41-80, 1979; GIERE, R. History and Philosophy of Science: Intimate Relationship or Marriage of Convenience? British Journal for the Philosophy of Science, v. 24, n.3, p. 282-297, 1973; BURIAN, R. More than a Marriage of Convenience: On the Inextricability of History and Philosophy of Science. Philosophy of Science, v. 44, n. 1 p. 1- 42, 1977.

$3 \quad$ KUHN, T. S. The Essential Tension. Chicago: UCP, 1977.

$4 \quad$ KUHN, T. S. The Structure of Scientific Revolutions. Chicago: University of Chicago Press, 1970b [1962], p. 3.

5 DELORME, A. Review of "Léonard de Vinci et la expérience scientifique au XVle siècle". Revue d'histoire des sciences et de leurs applications, v. 7, n. 4, p. 379-382, 1954, p. 379.

6 DIBNER, B. Leonard da Vinci, Man of Science. Science, New Series, v. 131, n. 3398, p. 380, 1960.

7 MIELI, A. Panomara General de Historia de la ciência. v. III, La eclosión del Renacimiento. Buenos Aires: Espasa-Calpe Argentina S.A., 1951 , p. 2.

8 Resenhas das obras de Sarton History of Science and the New Humanism e The Study of the History of Science, respectivamente. Os textos estão reunidos em METZGER, H. La méthode philosophique en histoire des science. Textes 1914-1939. Paris: Fayard, 1987.

9 METZGER, op. cit., 1987, p. 181.

10 dem, p. 185.

11 MILLÁS VALLICROSA, J. M. George Sarton y la Historia de la Ciencia Oriental. Isis, v. 48, n. 3, p. 315-319, 1957, p. 315.

12 Idem, p. 318.

13 KOYRÉ, A. "Les origines de la science moderne". In: KOYRÉ, A. Études d'histoire de la pensée scientifique. Paris: Gallimard, 1973 [1966], p. 61

14 A mais famosa obra de Sarton, publicada em três volumes: SARTON, G. Introduction to the History of Science. Baltimore: Williams and Wilkins, v. I, 1927; v. II, 1975 [1931] e v. III, 1975 [1947]. Doravante também mencionada como Introduction.

15 Ver, por exemplo, BARNES, H. E. Review of "The Life of Science: Essays in the History of Civilization". Annals of the American Academy of Political and Social Science, 263, p. 230-231, 1949, p. 230; MILLÁS VALLICROSA, op. cit., 1957, p. 315; SINGER, D.; SINGER, C. George Sarton and the History of Science. Isis, v. 48, n. 3, p. 306-310, 1957, p. 308.

16 FINKEL, J. Sarton on the History of Science. Review of "Introduction to the History of Science". v. 1. From Homer to Omar Khayyam. The Jewish Ouarterly Review, New Series, v.18, n. 4, p. 445-448, 1928, p. 448

17 ROLLER, D. A. D. A História da ciência e seu estudo nos Estados Unidos. In: ROLLER, D. A. D. et al. Iniciação à história da ciência. Tradução de Constantino Paleólogo. São Paulo: Cultrix, 1966, p.13.

18 CLAGETT, M. George Sarton: Historian of Medieval Science. Isis, v. 48, n. 3, p. 320-322, 1957, p. 322.

19 CROMBIE, A. C. Review of "The Appreciation of Ancient and Medieval Science during the Renaissance (1450-1600) e Six Wings. Men of Science in the Renaissance". The British Journal for the Philosophy of Science, v. 10. n. 38, p. 164-165, 1959, p. 164.

20 Ver KUHN, T. S. The Copernican revolution. Planetary Astronomy in the development of Western Thought. Cambridge: Harvard University Press, 1970a [1957], p. 283- 291. Introduction é mencionada nas notas do capítulo 4 (duas vezes: para abordagem da transição da ciência helênica para a helenística e para tratamento da astronomia europeia árabe e medieval). Além desse trabalho, Kuhn cita os seguintes escritos de Sarton: A History of Science: Ancient Science thought the Golden Age of Greece (para estudo da astronomia egípcia, mesopotâmica e helênica no contexto da ciência e cultura antigas) e Ancient Science and Modern Civilization (para estudo da ciência helênica e helenística).

21 BERNARD COHEN, I. George Sarton. Isis, v. 48, n. 3, p. 286-300, 1957.

22 STIMSON, D. Preface. In: SARTON, G. Sarton. On the History of Science. Ensaios selecionados e editados por Dorothy Stimson. Cambridge: Harvard University Press, p. v-x, 1962, p. v.

23 HELLMAN, C. D. George Sarton: Historian of Science and New Humanist. Science, 128, p. 641-644, 1958, p. 644

24 CLAGETT, op. cit., 1957, p. 321.

25 CROMBIE, op. cit., 1959, p. 164.

26 Nickles assinala uma mudança ocorrida na relação entre história e filosofia da ciência a partir do congresso de 1957, realizado em Wisconsin. Ver NICKLES, T. Philosophy of Science and History of Science. Osiris, Constructing Knowledge in the History of Science, v. 10, p. 138-163, 1955, p. 139.

27 KRAGH, H. An Introduction to the Historiography of Science. Cambridge: Cambridge University Press, 1989, p. 18.

28 RUPERT HALL, A. Can the History of Science be History? The British Journal for the History of science, v. 4, n. 3, p. 207-220, 1969, p. 215

29 GRANT, E. Physical Science in the Middle Ages. Cambridge: Cambridge University Press, 1987, p. 91.

30 RUPERT HALL, op. cit., 1969, p. 215.

31 Poucos são os trabalhos publicados sobre Sarton nos últimos dez anos. Ver SAYILI, A. George Sarton and the History of Science. Manchester: Foundation 
for Science, Technology and Civilization, 2005, p. 1-26; PYENSON, L. The Passion of George Sarton. A Modern Marriage and its Discipline. Philadelphia: American Philosophical Society, 2007. 0 primeiro apresenta um quadro sobre o prestígio de Sarton, com referência a alguns dos intérpretes aqui citados; o segundo, apesar de bastante extenso, foca mais a biografia de Sarton mais do que sua produção histórica.

32

SARTON, G. A History of Science: Ancient Science through the Golden Age of Greece. Cambridge: Harvard University Press, 1959[1952], p. vii.

SARTON, op. cit., 1927, p. 3.

SARTON, G. Introduction to the History and Philosophy of Science (Preliminary Note). Isis, v. 4, n. 1, p. 23-31, 1921, p. 23.

SARTON, op. cit., 1921, p. 23.

Idem, p. 23.

Idem, p. 24.

Idem, p. 25.

Cf. SARTON, op. cit., 1921, p. 27-29.

SARTON, op. cit., 1921, p. 31

Cf. SARTON, op. cit., 1975, v. II, p. v; v. III, p. 5.

SARTON, op. cit., 1927, p. 4.

Idem, p. 25.

SARTON, op. cit., 1975, v. II, p. vi.

SARTON, op. cit., 1975, v. III, p.vii.

SARTON, op. cit., 1975, v. II, p. vii.

Idem, p. viii.

Idem, p. viii.

Idem, p. ix.

SARTON, op. cit., 1975, v. III, p. xii.

dem, p. 3.

SARTON, G. Historians and Philosophers of Science. Isis, v. 46, n.4, p. 360-366, 1955, p. 361.

THACKRAY, A.; MERTON, R. On Discipline Building: The Paradoxes of George Sarton. Isis, v. 63, n. 4, p. 472-495, 1972, p. 495.

A bibliografia das publicações sartonianas, disponível em STRELSKY, Katharine. Bibliography of the publications of George Sarton. Isis, v. 48, n. 3, p. 336350, 1957, revela a dimensão do trabalho do historiador comprometido com o fornecimento de uma base para os estudos históricos do desenvolvimento da ciência.

0 livro a que se refere é $A$ estrutura das revoluções científicas. Note que o livro é, nesse texto, visto como pertencente à história da ciência. BERNARD COHEN, I. Revolution in Science. Cambridge: Harvard University Press, 1994 [1985], p. 22-23.

Entre os nomes de Alexandre Koyré, Émile Meyerson e Anneliese Maier, aparece o de Hélène Metzger. Ver KUHN, op. cit., 1970b, p. vi, nota 1

KUHN, op. cit., 1977, p. 148

Idem, p. 148

Idem, p. 148

Cf. BUTTERFIELD, H. The Whig Interpretation of History. New York: W. W. Norton \& Company, 1965[1931]. 0 adjetivo whig, introduzido por Butterfield, para designar a atitude dos historiadores que investigam o passado a partir de um ponto de vista determinado por valores e padrões de seu momento presente, foi empregado em relação a Sarton por outros críticos. Ver, por exemplo, RUPERT HALL, A. On Whiggism. History of Science, v. 21, p. 45-59, 1983.

KUHN, T. S. The Road since Structure. Chicago: University of Chicago, 2000, p. 282.

KUHN, 1977, op. cit., p. 3.

Idem, p. 15.

Idem, p. 4.

Idem, p. 15.

Tome-se, como exemplo, a argumentação kuhniana presente em "Tradição matemática versus tradição experimental no desenvolvimento das ciências físicas" em KUHN, op. cit, 1977, p. 31-65. Science, de Herbert Dingle, numa resenha de 1953, quando afirma que a verdadeira novidade do programa de Dingle é a "reiterada insistência de que o estudo histórico da ciência fornece uma ferramenta, talvez a ferramenta essencial para a compressão e a direção da pesquisa científica". KUHN, T. S. 1953. Review of "The Scientific Adventure: Essays in the History and Philosophy of Science by Herbert Dingle". Speculum, v. 28, n. 4, p. 879-880, p. 880. Logo a seguir, admitindo que os ensaios filosóficos são mais "originais e penetrantes" do que os ensaios históricos analisados, conclui que o "insucesso em explorar os insights históricos reforça a impressão de que o conceito de ciência de Dingle tem, até agora, extraído muito pouco da história".

68 KUHN, op. cit., 1977, p. 109.

69 SARTON, p. cit., 1975, v. II, p. viii.

70 RUPERT HALL, op. cit., 1969, p. 215. Ao lado deste intérprete, lembramos a caracterização sartoniana de Leonardo da Vinci, marcada pela admiração, por um lado, e, por outro, pela censura do grande gênio não ter sido completamente moderno na medida em que se manteve sujeito ao peso da tradição. Sarton, em diversas partes de sua obra, lamenta o fato de Leonardo ter ficado preso a preconceitos galênicos e platônicos e, por isso, não ter podido 
encontrar "a verdade". Ver, por exemplo, SARTON, G. The Life of Science. New York: Henry Schuman, 1948, p. 9 e SARTON, G. Sarton. On the History of Science. Ensaios selecionados e editados por Dorothy Stimson. Cambridge: Harvard University Press, 1962, p. 137.

71 DRABKIN, I. E. Commentary on the Papers of A.C. Crombie and Joseph T. Clark. In: CLAGETT, M. (ed.). Critical Problems in the History of Science. Madison: University of Wisconsin Press, p. 141-152, 1969, p. 149.

72 Sarton frequentemente definiu a ciência como "conhecimento positivo sistematizado". Ver, por exemplo, SARTON, op. cit., 1927, p. 3; SARTON, G. The Study of the History of Science. New York: Dover Publications, 1957, p. 5 e SARTON, op. cit., 1962, p. 1. Ele admitiu claramente a influência de Augusto Comte em seu trabalho. Ver, por exemplo, SARTON, op. cit., 1962, p. 7-8, 10, 28.

$73 \quad$ NICKLES, op. cit., 1995, p. 138; 153.

[Recebido em Julho de 2015. Aprovado para publicação em Maio de 2016] 